The following paper posted here is not the official IEEE published version. The final published version of this paper can be found in the Proceedings of the IEEE Power Electronics Specialist Conference (37th : 2006 : Jeje, South Korea):pp.1-7

Copyright (c) 2006 IEEE.

Personal use of this material is permitted. However, permission to reprint/republish this material for advertising or promotional purposes or for creating new collective works for resale or redistribution to servers or lists, or to reuse any copyrighted component of this work in other works must be obtained from the IEEE. 


\section{An Investigation of Advanced Magnetic Materials for Axial Field Brushless Permanent Magnet Motor Drives for Automotive Applications}

\author{
Gene Shane Liew*, Nesimi Ertugrul and \\ Wen Liang Soong \\ School of Electrical \& Electronic Engineering \\ University of Adelaide, \\ Adelaide, Australia \\ Email: *gliew@eleceng.adelaide.edu.au
}

\begin{abstract}
This paper investigates the operating characteristics of two emerging magnetic materials, amorphous magnetic material and soft magnetic composite, and aims to address specifically the iron losses in inverter-driven high speed electric machines for automotive applications. In the paper, a three phase brushless axial field permanent magnet machine is considered due to its compact shape and its high torque, power density and efficiency. 3D finite element analysis (FEA) was used to model and analyze axial field machines that utilize such magnetic materials. A cut version of amorphous magnetic material has been used successfully in the stator, and a direct comparison of amorphous magnetic material and soft magnetic composite stators are also given. The paper presents detailed test results to examine the influence of rotor magnet design, magnet type and air gap length, and provides the performance characteristics of the motor configuration, including drive and motor efficiencies. In addition, a number of motor parameters were simulated using the 3D FE analysis tool, including backEMF profile and cogging torque.
\end{abstract}

\section{INTRODUCTION}

In recent years, the requirements for better performance, safety, reliability, and lower cost and emissions in automobiles have driven the development of electrical machines using innovative materials and design techniques. Some of the targeted automotive applications include energy storage devices, starter/alternators, wheel traction motors, auxiliary machines and superchargers.

In addition, the introduction of variable-speed motor drives in these applications offers higher efficiency over a wide range of operating conditions. Furthermore, there is a trend in automotive applications to increase the operating speed of electric motors for a given output power in order to achieve size, weight and cost reductions. Although using variable-speed drives (motor and power electronics) can save significant amounts of energy, the losses in electrical machines constrain the overall efficiency of the drive, specifically during high speed operation. Moreover, the output characteristics of electrical machines and their production cost have also a significant effect on their selection.

Two sources of losses in machines are copper loss in the stator winding and iron loss in the magnetic core. Better utilization of copper in the magnetic circuit design can reduce the copper losses. The iron losses in machines however, are strongly affected by the frequency of the excitation, which is proportional to the speed of the machine. In order to reduce iron losses it is important to consider using alternative magnetic materials in the core of the machines.

\author{
John Gayler \\ Glassy Metal Technologies Ltd, \\ Adelaide, Australia \\ Email: johngayler@chariot.net.au
}

Despite rapid advancements in the areas of power electronics and controls, the basic construction of electric motors has remained unchanged for over a hundred years. Most machines today utilize some form of silicon iron (SI) as the core material. Two alternative magnetic materials have recently been developed: amorphous magnetic material (AMM) and soft magnetic composite (SMC), which can each offer unique characteristics which can be utilized to reduce the iron losses in electric machines.

Figures 1 and 2 provide a comparison of SI, AMM and SMC materials in terms of their $\mathrm{BH}$ curves and iron losses. AMM offers extremely low iron loss at high frequencies, and has high permeability and good magnetic properties compared to SI. Although SMC has higher iron losses than SI at $50 \mathrm{~Hz}$, it offers lower iron losses at higher frequencies, which is important in high-speed motor drive applications. Furthermore, SMC is a promising magnetic material particularly for small machines. It has a potential for low cost manufacturing and allows the construction of complex 3D machine geometries. In addition, SMC has low eddy current losses due to its high resistivity, but has relatively low permeability and low mechanical strength. Although SMC has high hysteresis losses compared to SI, the iron loss of SMC becomes comparable to SI at higher frequencies.

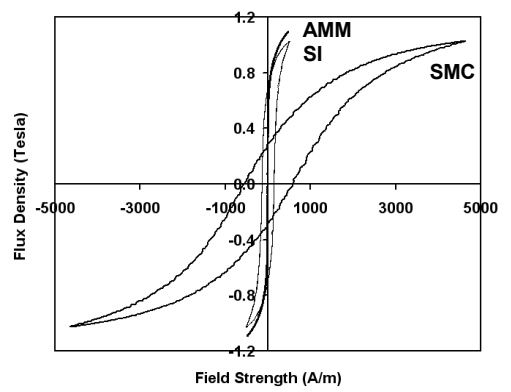

Fig. 1: Measured BH curves of SI (Lycore 230), SMC (Somaloy $550+0.6 \% \mathrm{LB} 1$ ) and AMM (Metglas, 2605SA1) at 50Hz, B=1T.

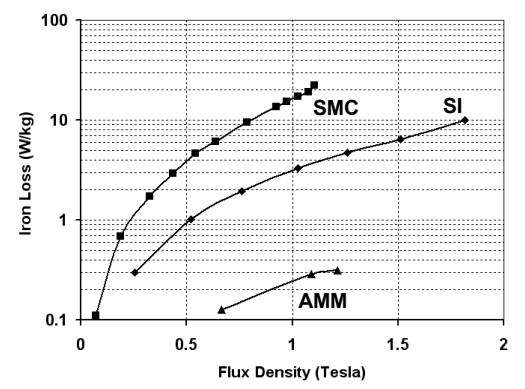

Fig. 2: Measured iron loss versus peak flux density for SI, SMC and AMM ring cores at $50 \mathrm{~Hz}$. 
Since the invention of AMM in the 1980s, very few studies utilizing AMM in motor applications have been reported in the literature. In [2], [3] and [4], stacked AMM laminations were used either in the stator or both the stator and rotor of radial induction and reluctance motors respectively. Core loss reductions of to $50 \%$ compared to SI based machines were demonstrated. In addition, an AMM based axial field brushless permanent magnet (PM) motor was reported in [5], which utilized an uncut tape-wound AMM in the stator core.

Despite the excellent magnetic properties of AMM, the difficulty and high cost in material handling and cutting have limited its major commercial application to power transformers. This is believed to be due to the lack of a viable, accurate and cost effective cutting technology. Recent developments in this area show promising results to overcoming this issue [9] which could allow AMM to be more widely used in electrical machines.

In various applications, axial-field permanent magnet (AFPM) machines are gaining popularity primarily due to their compact shape, higher torque and power density, and higher efficiency [6, 7 and 8]. In addition, AFPM machines are well suited to the use of AMM due to their suitability to a tape-wound structure.

Therefore, this paper considers a motor design to utilize the benefits of an AFPM structure for automotive applications. Stators utilizing both AMM and SMC material were constructed, and the electrical characteristics of the motor configurations were investigated.

The paper utilized a finite-element package software, JMAG, to analyze the motor operation. In addition, a selected number of experimental results were given in this paper to investigate the influence of rotor magnet design and air gap length, and to provide the performance characteristics of the motor drives, including drive and motor efficiencies.

\section{AFPM MOTOR AND DRIVE SPECIFICATIONS}

Two identical small three-phase stator cores (a cut AMM lamination stator and a SMC stator) have been constructed. Their dimensions are as follows: outer diameter $32 \mathrm{~mm}$; inner diameter $11 \mathrm{~mm}$; and height $13 \mathrm{~mm}$. The stator cores used in the AFPM motor design are shown in Fig. 3. The AMM core was constructed by wrapping AMM ribbon into a coil and the three stator teeth were cut using the abrasive water jet technique developed in [9].

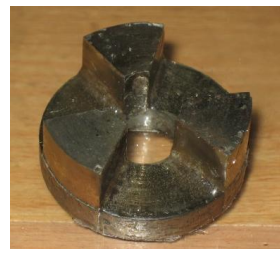

a

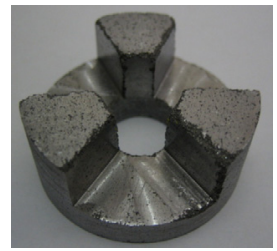

b

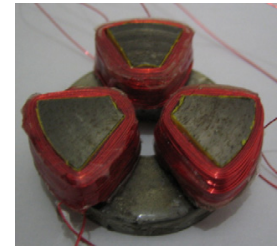

c
Fig. 3: The stator cores of the AFPM test motors a) using cut AMM ribbon b) using SMC c) a stator with windings $(9 \Omega, 5.2 \mathrm{mH})$

A number of rotor magnet configurations were designed and built based on the available commercial magnets as shown in Fig. 4.
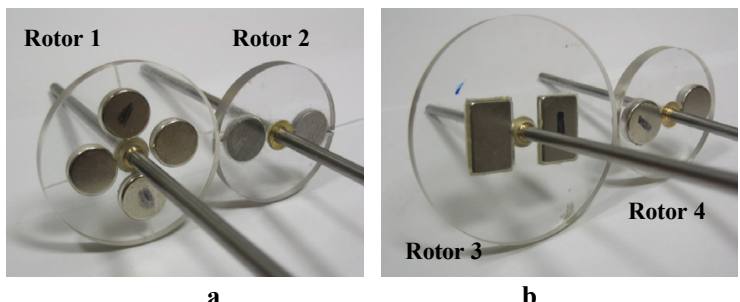

b

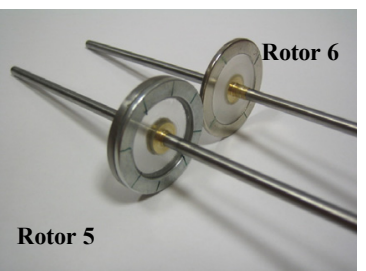

c

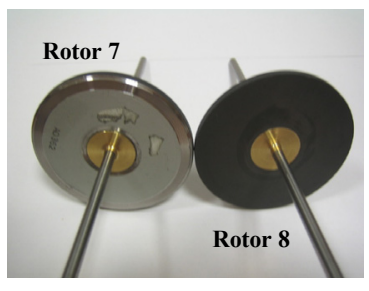

d
Fig. 4: The rotor configurations investigated:

a) 4 pole (Rotor 1 ) and 2 pole (Rotor 2 ) with $12 \mathrm{~mm}$ Neodymium disc magnet rotors.

b) 2 pole $20 \times 12.5 \mathrm{~mm}$ block (Rotor 3 ) and $15 \mathrm{~mm}$ disc (Rotor 4 ) Neodymium magnet rotors.

c) 8 pole with back iron (Rotor 5 ) and 4 pole without back iron (Rotor 6) Neodymium ring magnet rotors.

d) 8 pole with iron (Rotor 7) and without back iron (Rotor 8) Ferrite disc magnet rotors.

Figure 5 shows the custom-built flexible test setup. The setup is designed to test a wide range of axial flux stator and rotor configurations and to allow easy variation of the air gap length. The setup includes a high-speed DC machine (ASTRO - 15 Super Ferrite) for loading the AFPM motor configuration under test. A special attachment introduced in the test setup allows the variation of the axial air gap length of $0.5 \mathrm{~mm}$ up to $10 \mathrm{~mm}$ and within accuracy of $0.1 \mathrm{~mm}$. In addition, the setup is designed to achieve a good stability and rigidness during high speed operation and can accommodate motors up to $80 \mathrm{~mm}$ in diameter.

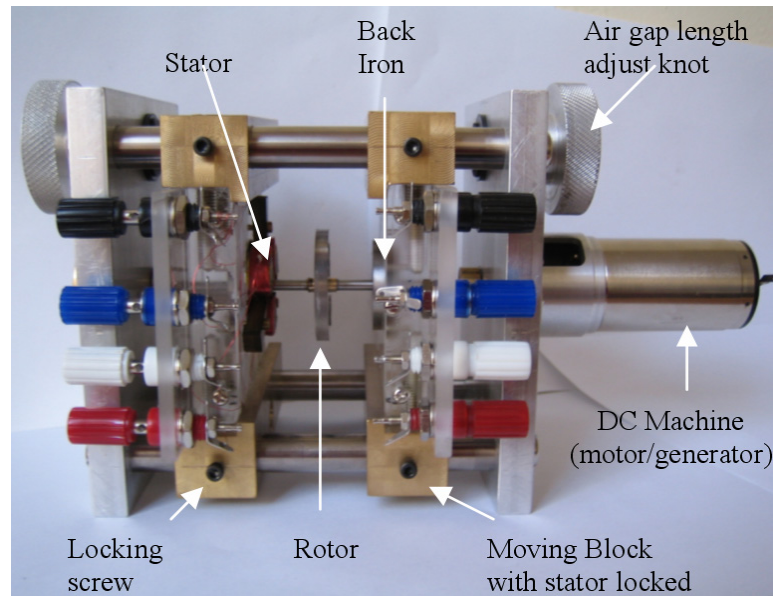

Fig. 5: The photo of the custom-built flexible test setup

Figure 6 shows the block diagram of the brushless AFPM motor drive, which was implemented to test the motor configurations considered. In the control system, the rotor 
position was obtained using three Hall-Effect sensors separated by $120^{\circ}$, which were excited by a separate custom-built PM disk.

The integrated inverter module (International Rectifier IRAMX16UP60A) receives the switching signals from the PIC16F877A microcontroller and generates the three-phase voltages for the star-connected motor. In the microcontroller, pulse-width modulation was implemented both to limit the starting current and to control the speed of the motor.

A power analyzer was also utilized in the setup to measure inverter input (dc) and output (ac) power.

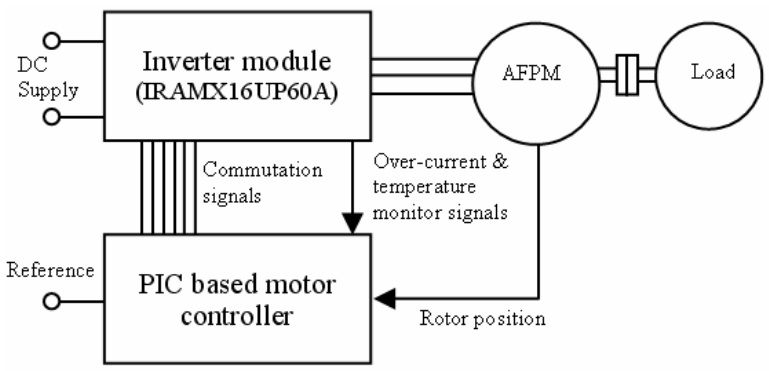

Fig. 6: The block diagram of the brushless AFPM motor drive

\section{FINITE ELEMENT MODELING OF THE MOTOR DRIVE}

Due to the complex 3D geometry of axial flux PM machines, conventional 2D finite-element methods (FEM) cannot be used. Therefore, the 3D FEM software package JMAG-Studio 8.0 was employed to simulate and predict the characteristics of the test motors.

At the initial stage of simulation study, as JMAG provided built-in SMC material characteristics, the performance of the SMC stator core was modeled for verification. Due to the lack of symmetry in the test machine, the complete stator and rotor needed to be modeled. Figure 7 illustrates a sample 3D mesh (with 80,068 elements and 13,937 nodes) and a view of the magnetic flux density vectors for the SMC stator and rotor 2.
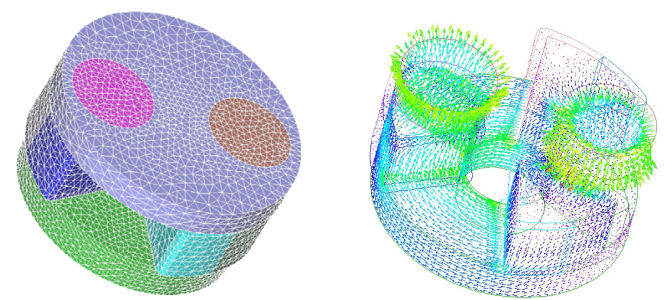

Fig. 7: 3D FEM models of a AFPM motor configuration, mesh model (left) and magnetic flux density vector display (right)

Figure 8 shows the simulated and measured back-EMF waveforms for various air gap lengths for the stator/rotor configuration considered in Fig. 7. There is a good correspondence between the simulated and measured results which gives confidence in the accuracy of the $3 \mathrm{D}$ finite-element modeling approach used. The small discrepancies in their amplitudes that may be due to slight variations in the air gap length in the test setup.

Figures 9 and 10 were used to verify the measured phase voltage and current waveforms of the motor drive. The simulation results are from a time-stepping coupled-circuit 3D finite-element simulation. The simulation results are in good agreement with the measured waveforms. The discrepancies in the waveforms may be due to high flux leakage and the switching losses of the power module that were not considered in the simulation.

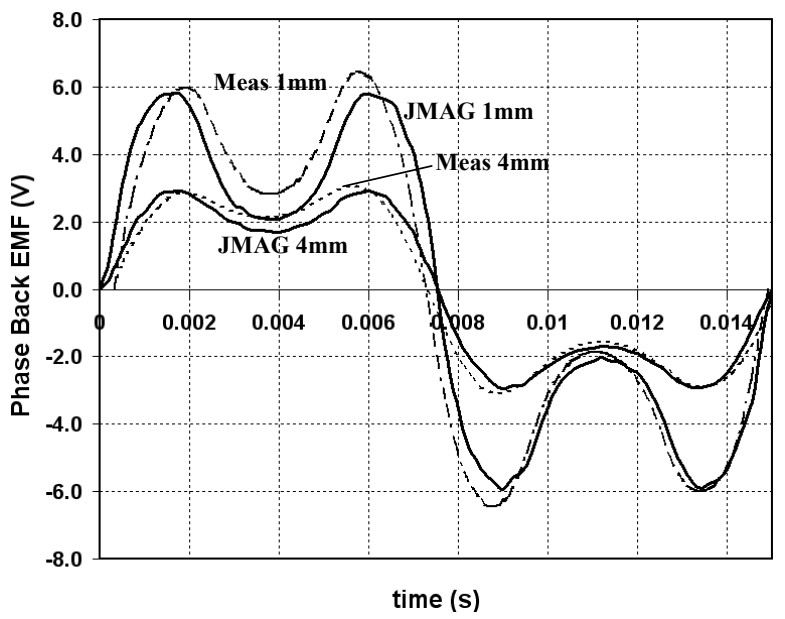

Fig. 8: Simulated and measured phase back-EMF waveforms

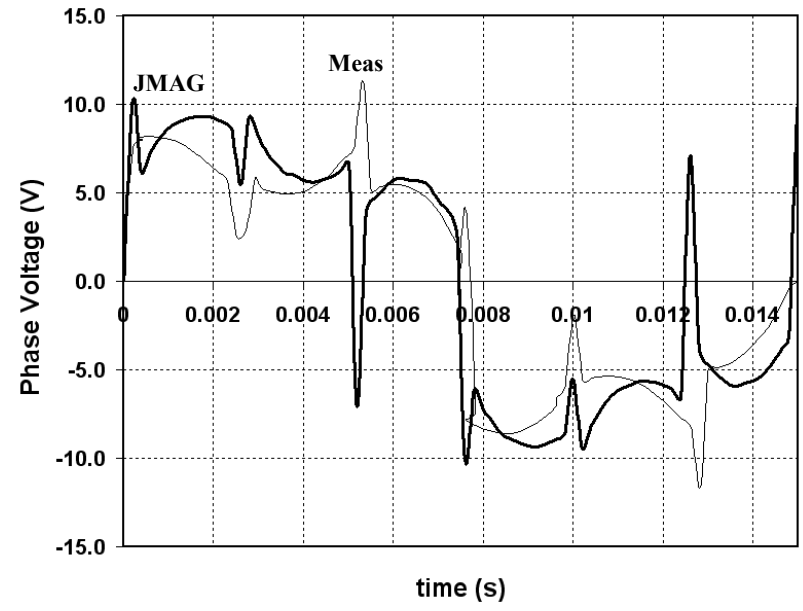

Fig. 9: Simulated and measured phase voltage waveforms

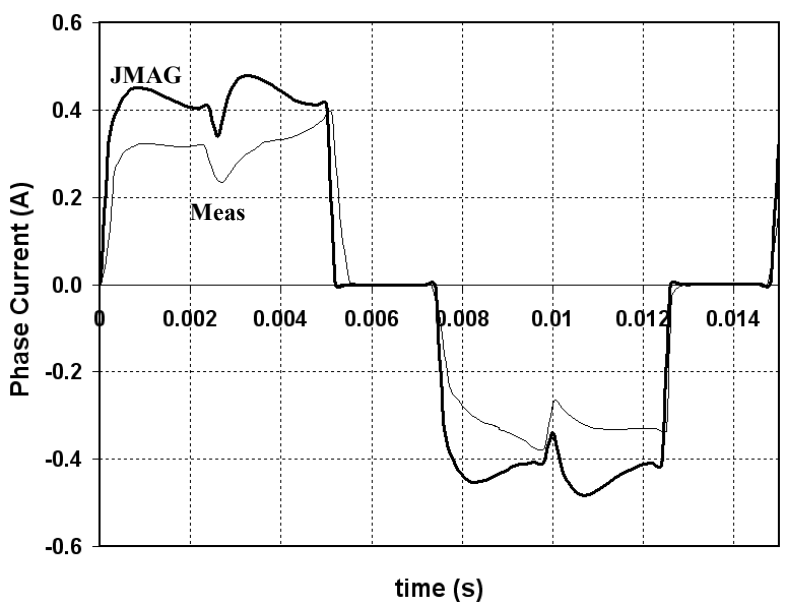

Fig. 10: Simulated and measured phase current waveforms 
Figures 11 and 12 provide the simulated plots for the axial force and the cogging torque. These were obtained under zero excitation in the 3D FEM tool. Due to hardware and time limitation it was not possible to obtain experimental confirmation of these results.
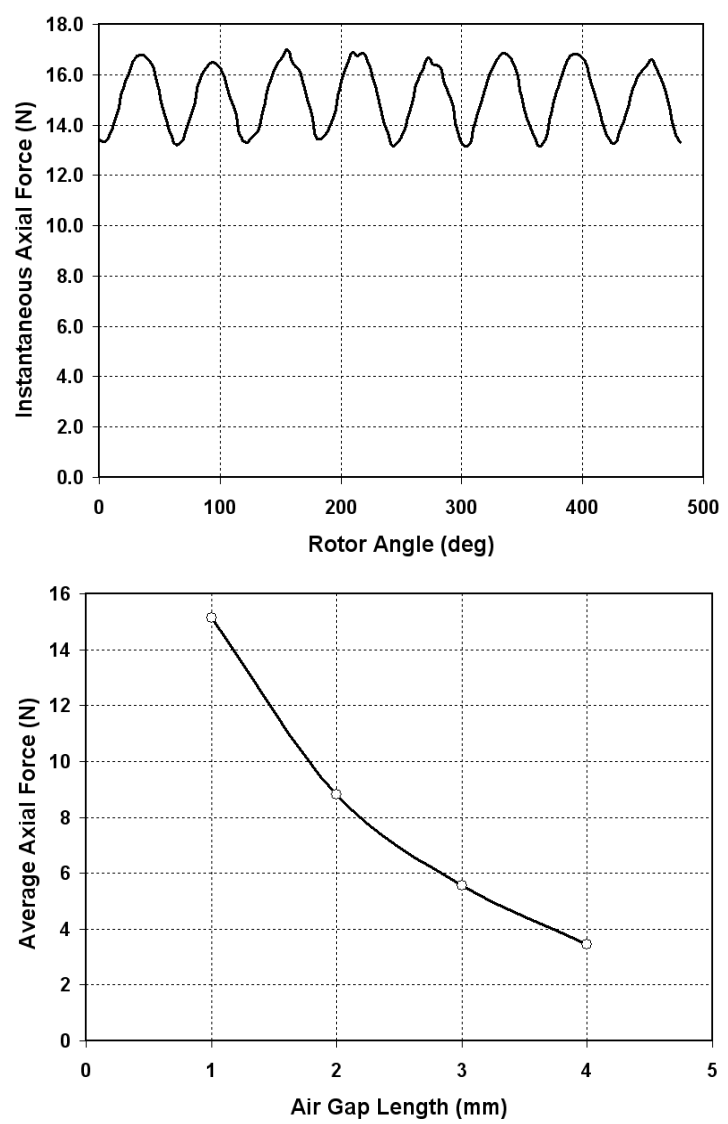

Fig. 11: Simulated instantaneous force as a function of rotor angle (top) and simulated average force as a function of air gap length (bottom)

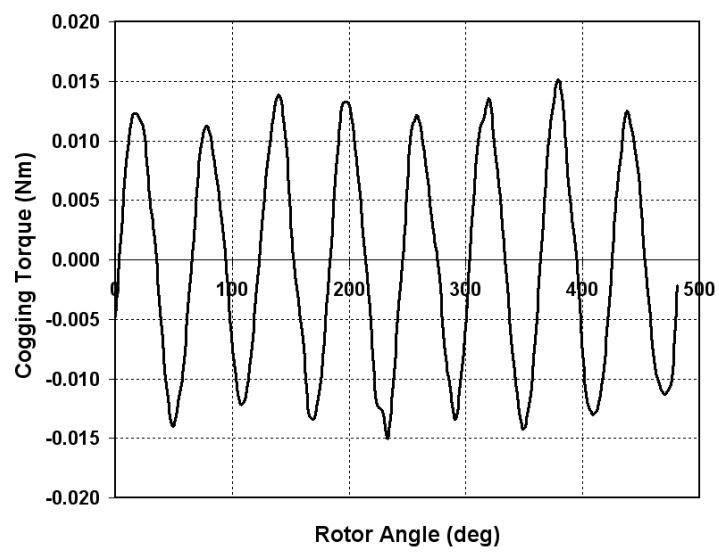

Fig. 12: Simulated cogging torque as a function of rotor angle, $1 \mathrm{~mm}$ air gap

Figure 11 shows that the single-sided configuration has large axial forces (about $15 \mathrm{~N}$ for a $1 \mathrm{~mm}$ air gap) which can produce large bearing losses. In order to reduce the axial force, a double-sided stator design (i.e. two stators, one on each side of the disc rotor) can be utilized. The average axial force decreases as the air gap length increases due to higher flux leakage as shown in Fig. 11 (bottom).
The predicted cogging torque as a function of rotor position is given in Fig. 12, which can be considered acceptable for the AFPM motor under test taking into account its salient pole structure.

\section{PERFORMANCE CHARACTERISTIC STUDIES}

\section{A. Influence of Rotor Configurations and Magnet Type}

A number of tests were performed to study the relationship between the rotor configurations and the back-EMF waveforms. Figure 13 shows the back-EMF waveforms of the rotor configurations given in Fig. 4, which are scaled for clarity. All the results were obtained under identical operating conditions: at a speed of approximately $4000 \mathrm{rpm}$ and an air gap of $1 \mathrm{~mm}$.

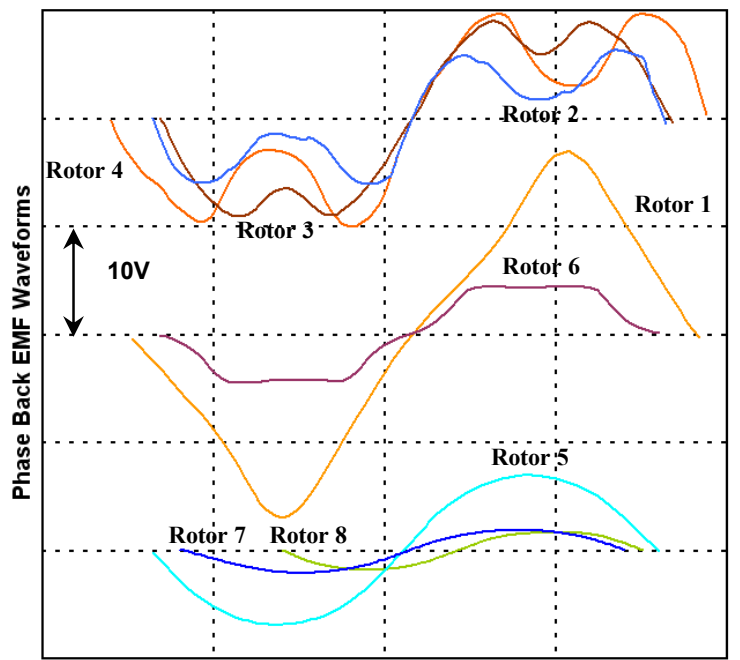

Fig. 13: Phase back-EMF waveforms for various rotor configurations at 4000rpm and with a1 mm air gap.

The test results revealed that, as expected, the pole-arc of the magnets has a direct influence on the dip in the back-EMF waveform. A smooth flat top was observed in the back-EMF waveform for the rotor configuration having 4 pole ring shape magnets which has nearly 180 degrees pole-arc (Rotor 6). However, no flat top was observed for the 8 pole ring shape magnet with back iron and smaller north and south poles continuous sections (Rotor 5). Moreover, it was observed that using back iron in the rotor changes the back-EMF shape and increases its amplitude.

The magnitude of the back-EMF waveforms for the rotors with ferrite magnets were about $50 \%$ less than the neodymium magnet rotors. This is also due to the shape of the magnets covering small portion of the pole areas of the stator teeth.

Table I compares the performance for the same output torque and speed of the motor configurations with 2 pole rotors with neodymium magnets of different size and shape (see Fig. 4). The three rotor types have significantly different efficiencies due to variations in the iron and copper losses. For example Rotor 2 has the smallest back-EMF constant and so requires the highest current to generate the same level of output torque. This results in the highest copper loss and 
hence the lowest efficiency. Rotor 4 which has slightly larger magnets than Rotor 2, offers $15 \%$ greater efficiency due to its higher back-EMF constant. Finally, Rotor 3 with the largest magnets has the highest back-EMF constant and hence the highest efficiency.

TABLE I

COMPARISON OF PERFORMANCE USING ROTOR WITH NEODYNIUM MAGNETS (a) 2500RPM, AMM STATOR, AIR GAP 1MM

\begin{tabular}{|c|c|c|c|c|c|c|}
\hline Rotor & $\begin{array}{c}\text { EMF } \\
\text { constant } \\
\text { V/rad/s }\end{array}$ & $\begin{array}{c}\text { No load } \\
\text { loss } \\
\text { W }\end{array}$ & $\begin{array}{c}\text { Output } \\
\text { Power } \\
\text { W }\end{array}$ & $\begin{array}{c}\text { Iron } \\
\text { Loss } \\
\text { W }\end{array}$ & $\begin{array}{c}\text { Copper } \\
\text { Loss } \\
\text { W }\end{array}$ & $\begin{array}{c}\text { Efficiency } \\
\%\end{array}$ \\
\hline 2 & 0.009 & 0.58 & 1.80 & 0.33 & 2.78 & 37 \\
\hline 3 & 0.016 & 0.50 & 1.70 & 0.30 & 0.82 & 61 \\
\hline 4 & 0.015 & 0.55 & 1.80 & 0.46 & 1.14 & 53 \\
\hline
\end{tabular}

It should be noted here that the back-EMF waveform together with the current excitation method implemented in the brushless PM motor drives directly affect the shaft torque ripple.

\section{B. Influence of Air Gap Length}

The air gap length is an important parameter in axial-field PM machines as it affects the machine's output torque and efficiency.

Measurements of the iron loss, back-EMF voltage and efficiency were conducted for both AMM and SMC stators and under four different air gap lengths: $1 \mathrm{~mm}, 2 \mathrm{~mm}, 3 \mathrm{~mm}$ and $4 \mathrm{~mm}$. The selected set of results given in Fig. 14 were obtained using the 2 pole rotor configuration shown in Fig. $4 \mathrm{~b}$ (Rotor 3). This rotor was chosen as it gave the highest efficiency.

The iron loss characteristic shown in Fig. 14 (top) was obtained from the measured open-circuit torque loss versus speed characteristic of the motor when driven by a DC machine. As can be seen, the iron loss increases with speed but decreases with air gap length.

The phase back-EMF is linearly proportional to speed and decreases as the air gap length increases as shown in Fig. 14 (middle). From these results, the use of a small air gap in AFPM motors result in a higher back-EMF but higher iron losses.

Furthermore, as shown in Fig. 14 (bottom), for a constant air gap length, increasing the output torque decreases the efficiency. This is because copper losses are dominant in this design (see Table 1) and so the losses are proportional to the square of the current while the output power is proportional to the current. This figure also shows that for a given torque, increasing the air gap length reduces the back-EMF which increases the required current and hence reduces the efficiency.

It was found that the motor input current was significantly affected by the no-load loss torque of the DC load machines (low inertia ESCAP34L11 and ASTRO-15 motors). As a result of the tests, it was found that the no-load loss of the two DC motors was observed to be about 10 times higher for ASTRO-15 motor compared to ESCAP motor.
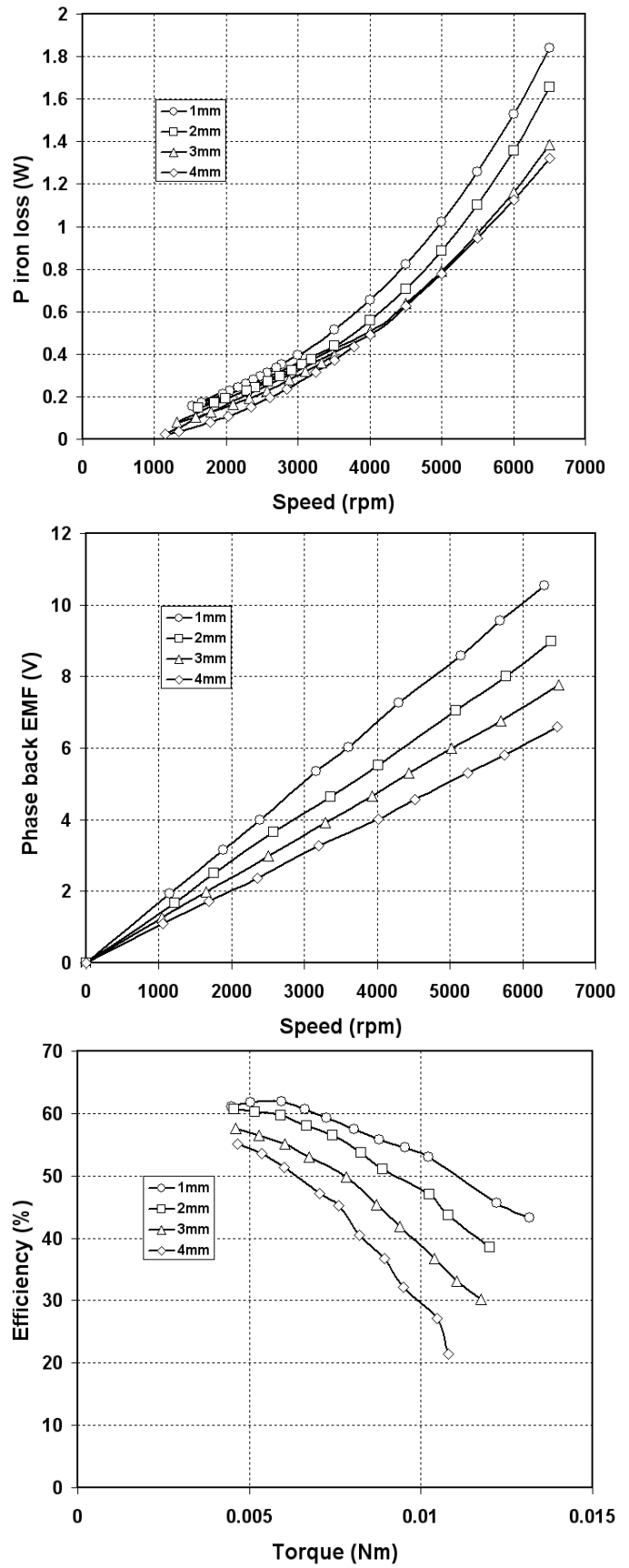

Fig. 14: Performance characteristics of the motor drive under constant voltage and varying air gap lengths: iron loss versus speed (top), phase back EMF E versus speed (middle), and efficiency versus output torque (bottom).

Furthermore, it was found that a given test machine was able to achieve a speed of 5500rpm with ESCAP DC motor but only a speed of 3500rpm with ASTRO-15 DC motor. However, the ESCAP machine was unable to drive the rotor shaft as high torque is required to overcome the strong cogging torque of the machine. This effect was especially important for small air gap lengths and for the AMM stator which has high permeability.

Table II shows the efficiency of the motor drive obtained by measuring the input and output powers of the inverter using a digital power meter (YOKOGAWA, model WT1600) for the AMM stator. An inverter efficiency of 15-16\% was 
measured for different rotor configurations and air gap lengths. The low inverter efficiency is primarily due to the low rated output voltage and power of the test motor compared to the inverter rating. Similar efficiencies were also observed for SMC stator.

TABLE II

INVERTER EFFICIENCY \% FOR DIFFERENT ROTOR AND AIR GAP LENGTH

\begin{tabular}{|c|c|c|c|c|c|}
\hline \multirow[t]{2}{*}{ Rotor } & \multirow{2}{*}{$\begin{array}{c}\text { Speed } \\
(\mathrm{rpm}) \\
1 \mathrm{~mm}\end{array}$} & \multicolumn{4}{|c|}{ Air Gap Length } \\
\hline & & $1 \mathrm{~mm}$ & $2 \mathrm{~mm}$ & $3 \mathrm{~mm}$ & $4 \mathrm{~mm}$ \\
\hline 1 & 1,900 & 15.1 & 15.2 & 15.2 & 15.2 \\
\hline 2 & 3,540 & 15.5 & 15.0 & 15.7 & 15.7 \\
\hline 3 & 2,760 & 15.7 & 15.8 & 15.9 & 15.9 \\
\hline 4 & 2,930 & 15.5 & 15.6 & 15.7 & 15.5 \\
\hline
\end{tabular}

\section{Comparisons of AMM and SMC}

The AMM and SMC stators have identical dimensions and have identical stator windings. They were tested with the same rotor (Rotor 3 ) and the measured parameters are given in Table III. This shows that the stators have similar back-EMF constants, coil inductances and coil resistances. The AMM based motor offers 50\% less iron loss than the SMC based motor. It was expected that the AMM stator should offer significantly lower iron loss than SMC by at least an order of magnitude (see Fig. 2). The difference may be associated with extra losses associated with the three-dimension flux distribution in the machine which could cause fluxes which are perpendicular to the laminated direction. This issue requires further investigation.

TABLE III

COMPARISON OF PARAMETERS AT 3000RPM, AIR GAP 1MM

\begin{tabular}{|c|c|c|c|c|}
\hline Stator & $\begin{array}{l}\text { EMF } \\
\text { constant } \\
\mathrm{V} / \mathrm{rad} / \mathrm{s}\end{array}$ & $\begin{array}{c}\text { Coil } \\
\text { Inductance } \\
\mathrm{mH}\end{array}$ & $\begin{array}{c}\text { Coil } \\
\text { resistance } \\
\Omega\end{array}$ & $\begin{array}{c}\text { Iron } \\
\text { Loss } \\
\mathrm{W}\end{array}$ \\
\hline $\mathrm{AMM}$ & 0.016 & 5.0 & 9 & 0.4 \\
\hline $\mathrm{SMC}$ & 0.016 & 4.7 & 8.9 & 0.8 \\
\hline
\end{tabular}

The factors affecting the efficiency of the motors under load are summarized in the following figures. Figure 15a shows the components of the power losses (copper and iron) and the output power. In Fig. 15b, the efficiency versus output torque characteristics are given.

It can be observed in Fig. 15 that as the load increases the speed of the motor decreases, and the AMM based motor develops slightly higher torque than the SMC motor. In addition, the efficiency of the AMM machine is also higher but the difference decreases as output torque increases. This can also be observed in Fig. 15a from the substantial increase of the copper loss as the load increases.

As shown in Fig. 15a, about 50\% higher iron loss was measured in the SMC based motor using Rotor 3. However, for other rotor configurations, the smaller percentage of iron loss was observed in both types of stator.
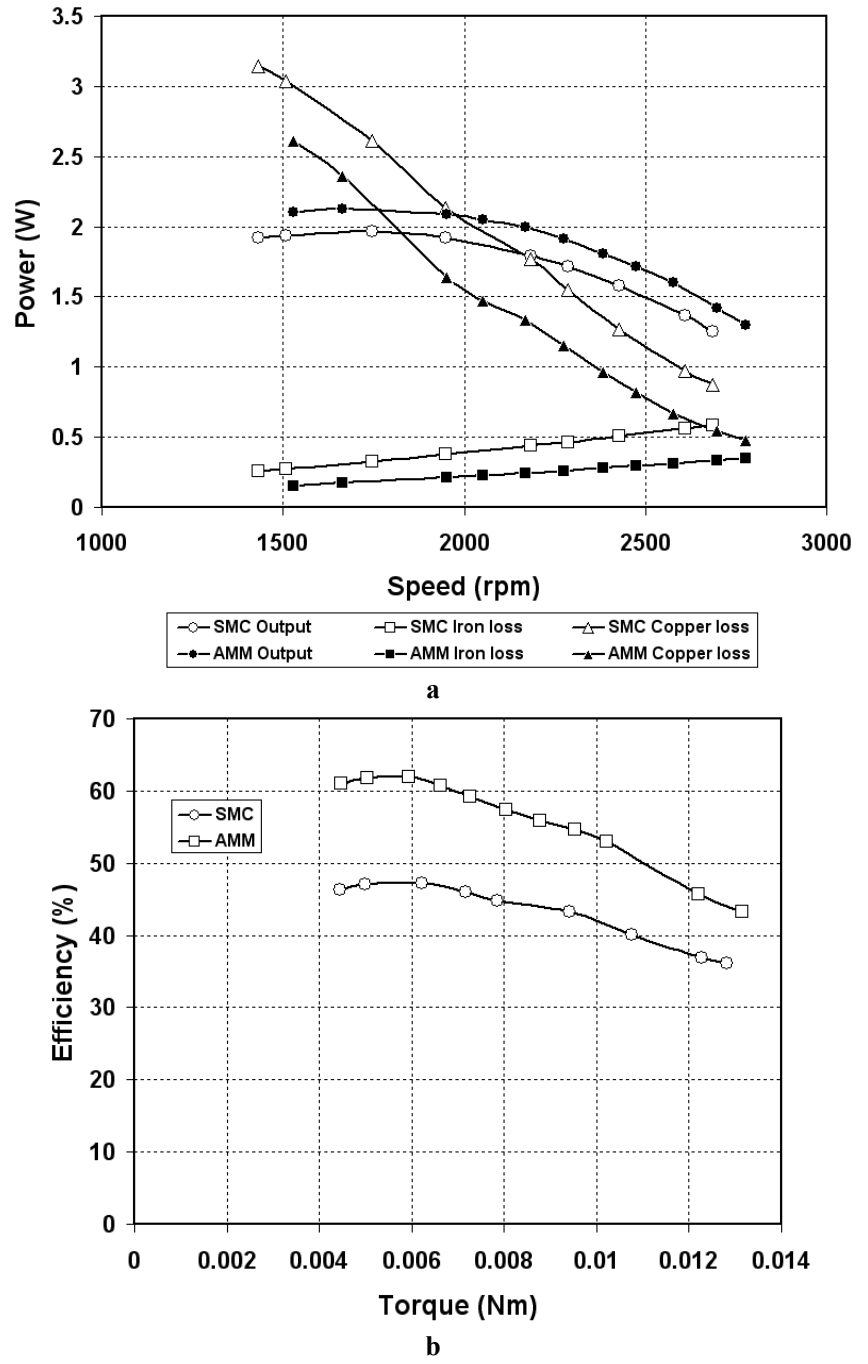

Fig. 15: Load tests for AMM and SMC motors:

a) Components of power characteristics (output power, iron loss and copper loss) versus speed, at constant voltage of $15 \mathrm{~V} \mathrm{dc}$ and at an air gap of $1 \mathrm{~mm}$. b) Efficiency versus output torques.

Similar results to those described above, were observed for other rotor configurations, in which the AMM core offers slightly higher output torque and lower copper and iron losses compared to the SMC core. As a result, significantly higher efficiency is achieved in the AMM core. However, the high permeability of AMM and the high magnetic flux of the neodymium magnets create a strong axial force in the AFPM motor. Therefore, a higher no-load loss was observed in the AMM stator and Rotor 1 (4 pole Neodymium magnets) configurations specifically at smaller air gap lengths as shown in Fig. 16a. This results in smaller output torque and higher copper loss.

However, the effect is minor for the SMC core. As seen in Fig. 16b, a lower efficiency is observed only at $1 \mathrm{~mm}$ air gap length. Therefore, about 50\% higher efficiency is achieved in the SMC based motor using Rotor 1. As indicated above, the efficiency of the AMM machine was greatly affected by the attractive force, which will be addressed in the future studies. 

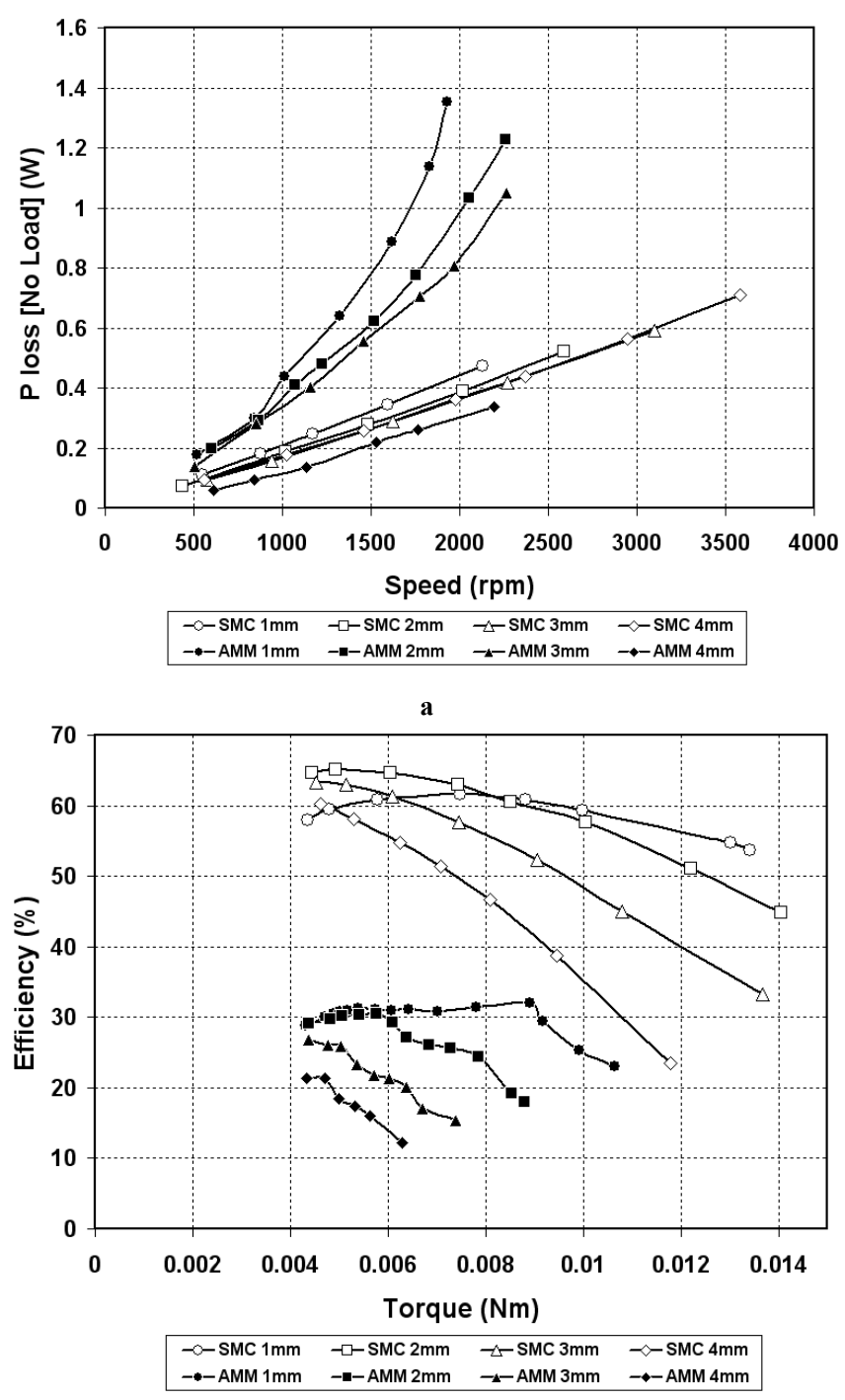

Fig. 16: Load tests of the AMM and SMC motors at various air gap lengths:

a) No load loss versus speed characteristics

b) Efficiency versus output torque characteristics

\section{CONCLUSION}

This paper investigated the performance of an axial-field permanent magnet motor utilizing two emerging magnetic materials, cut AMM and machined SMC.

The motor configurations were modeled by a 3D FE based electromagnetic analysis tool and tested using a custom built test setup. In the simulation study, the characteristics of the motor configurations and the accuracy of the finite-element prediction were investigated. The entire motor drive was also implemented to study the motor as well as the inverter characteristics.

The key results are:

- In the motor design, the shape and amplitude of the back-EMF waveforms are affected by the magnet type, magnet spacing and the presence of rotor back iron. Higher efficiency is achievable with higher values of back-EMF constant associated with larger magnet pole areas.
- Larger air gap length offers smaller iron loss but smaller back-EMF constant. For the test motors considered where copper loss is dominant, increasing the air gap length decreases efficiency due to the significant increase in input current and hence copper losses.

- Higher torque and efficiency is achievable with the AMM stator compared to the SMC stator. However, the axial force is significantly larger with the AMM stator which has a significant influence on efficiency due to the increased no load bearing drag losses.

- The results from the 3D finite-element analysis modeling tool utilized in this study showed good correspondence with the measured performance of the axial-field PM machines.

\section{ACKNOWLEDGMENT}

The authors would like to thank the Australian Research Council (ARC Linkage Project: LP0455574) for supporting this project; the staff of the School of Electrical and Electronic Engineering's mechanical workshop for construction of the test-rig; and S.I. Brand for support in the testing.

\section{REFERENCES}

[1] Liew, G.S., Ertugrul, N., Soong, W.L. and Gayler, J., "Investigation of Axial Field Permanent Magnet Motor Utilizing Amorphous Magnetic Material", Australasian Universities Power Engineering Conference (AUPEC) 2005, Hobart.

[2] Johnson, L.A., Cornell, E.P., Bailey, D.J. and Hegyi, S.M., "Test Results on A Low Loss Amorphous Iron Induction Motor", IEEE Transactions on Power Apparatus and Systems, Vol. PAS-101, No.7, pp. 2907-2911, July 1982.

[3] Rosenberry, G.M., Frischmann, P.G., and Tompkins, R.E., "Applications of Low Loss Amorphous Metals in Motors and Transformers", IEEE Transactions on Power Apparatus and Systems, Vol. PAS-100, No.6, pp. 2109-2114, June 1981.

[4] Fukao, T., Chiba, A., and Matsui, M., "Test Results on a Super High Speed Amorphous Iron Reluctance Motor", IEEE Transactions on Industry Applications, Vol. 25, No.1, pp. 119-125, January/February 1989.

[5] Jensen, C.C., Profumo, F. and Lipo, T.A., "A Low-Loss Permanent-Magnet Brushless DC Motor Utilizing Tape Wound Amorphous Iron", IEEE Transactions on Industry Applications, Vol. 28, No.3, pp. 646-651, May/June 1992.

[6] Wijenayake, A. H., Bailey, J.M., and McCleer, P.J., "Design Optimization of An Axial Gap Permanent Magnet Brushless DC Motor for electric Vehicle Applications", IEEE Industry Applications Conference 1995 Thirtieth IAS Annual Meeting, Orlando, FL, USA, 1995.

[7] Profumo, F., Zhang, Z. and Tenconi, A., "Axial Flux machines Drives: A new Viable Solution for Electric Cars", IEEE Transactions on Industrial Electronics, Vol. 44, No.1, pp. 39-45, February 1997.

[8] Press Releases, Light Engineering Inc, USA. Available: http://www.lightengineering.com/news.htm

[9] Rybak et al, US Patent 6,106,376, "Bulk Metallic Glass Motor and Transformer Parts and Method of Manufacture", August 22, 2000.

[10] JMAG-Studio 8.3 User's Manual Pre/Post (English version), JMAG-Studio Group, Engineering Technology Division, The Japan Research Institute, Ltd., Tokyo, Japan, 2005.

[11] Analysis of Axial Gap Motor Using "Patch Mesh" Function, JMAG-Studio Group, Engineering Technology Division, The Japan Research Institute, Ltd., Tokyo, Japan, 2005. 